\title{
Empowering Adolescent Mothers in the Choice of Contraceptive Methods at the Postpartum Period: Avoiding a Subsequent Pregnancy
}

\section{Empoderando mães adolescentes na escolha do método contraceptivo no pós-parto: Evitando-se a gravidez subsequente}

\author{
Anderson Borovac-Pinheiro ${ }^{1}$ Erica Almeida Ramos Jesus ${ }^{1}$ Fernanda Garanhani Surita ${ }^{1}$ () \\ ${ }^{1}$ Department of Tocogynecology, Medical Sciences School, \\ Universidade Estadual de Campinas, Campinas, SP, Brazil \\ Address for correspondence Fernanda Garanhani Surita, \\ Universidade Estadual de Campinas, Rua Alexander Fleming, 101, \\ 13083-881, Campinas, SP, Brazil (e-mail: surita@unicamp.br).
} Rev Bras Ginecol Obstet 2019;41:607-612.

\section{Abstract \\ Keywords \\ - contraception \\ - long-acting reversible contraception \\ - adolescent \\ - postpartum period \\ - antenatal education}

\section{Resumo}

Objective Almost $80 \%$ of adolescent pregnancies are unplanned, and between 28 and $63 \%$ of adolescent mothers had a repeated pregnancy within 18 months. Among girls with repeated pregnancies, two-thirds reported that the pregnancy was unplanned. We aim to assess contraceptive use by adolescent mothers with increasing choice for long-acting reversible contraception (LARC) methods in postpartum consultation after a semistructured group intervention involving adolescent mothers.

Methods Retrospective observational study conducted at the Universidade Estadual de Campinas, Campinas, state of São Paulo, Brazil, involving new antenatal and postpartum education groups for adolescents. At postpartum consultations, the adolescents chose their contraceptive. The data was compared with previous series followed in a period before the implementation of the education group - a historical control group.

Results We included 129 adolescent after childbirth from January $1^{\text {st }}, 2015$ through July $31^{\text {st }}, 2017$. Out of this total, $63 \%$ had ever used contraceptive methods before pregnancy, and the most frequent method was combined oral contraceptives (33\%) followed by condoms (21\%). At the first postpartum consultation, the most common contraceptive chosen was intrauterine contraception (IUC) (37.2\%) and depot-medroxyprogesterone acetate (DMPA) (34.1\%). When comparing the rates before and after the education interventions, there was a 3-fold increase in the use of IUCs.

Conclusion Antenatal and postpartum education have shown a significant increase in the choice for LARC methods among adolescent mothers, with very high acceptability after a period using the method. The educational groups performed during the antenatal care and beyond the gestational period are easy to be applied worldwide with low dependence on funding.

Objetivo Cerca de $80 \%$ das gestações na adolescência não são planejadas, e entre 28 e $63 \%$ das mães adolescentes apresentam repetição da gravidez em 18 meses. Entre as meninas com gravidez repetida, dois terços relataram que a gravidez não foi planejada. received

March 25, 2019

accepted

August 12, 2019
DOI https://doi.org/

10.1055/s-0039-1697985. ISSN 0100-7203.
Copyright $\odot 2019$ by Thieme Revinter

Publicações Ltda, Rio de Janeiro, Brazil
License terms

(c) (1) 


\author{
Palavras-chave \\ - contracepção \\ - anticoncepcional \\ reversível de longa \\ duração \\ - adolescente \\ - pós-parto \\ - educação pré-natal
}

Nosso objetivo é avaliar o uso de anticoncepcionais por mães adolescentes com crescente escolha para métodos de contracepção reversível de longa ação (LARCs, na sigla em inglês) na consulta pós-parto após uma intervenção em grupo semiestruturada envolvendo mães adolescentes.

Métodos Estudo observacional retrospectivo realizado na Universidade Estadual de Campinas, São Paulo, SP, Brasil, envolvendo novos grupos de educação pré-natal e pósparto para adolescentes. Nas consultas pós-parto, os adolescentes optaram pela contracepção. Os dados foram comparados com uma série de casos seguida em um período anterior à implementação do grupo de educação pré-natal - um grupo de controle histórico.

Resultados Foram incluídas 129 adolescentes no período pós-parto de $1^{\circ}$ de janeiro de 2015 a 31 de julho de 2017. Destas, 63\% já tinham usado métodos contraceptivos antes da gravidez, e o método prévio mais frequente foi contraceptivo oral combinado (33\%) seguido por preservativo (21\%). Na primeira consulta pós-parto, o anticoncepcional mais comumente escolhido foi o dispositivo intrauterino (DIU) $(37,2 \%)$ e o acetato de medroxiprogesterona de depósito (DMPA) (34,1\%). Ao comparar as taxas antes e depois das intervenções de educação pré-natal, houve um aumento de três vezes no uso de DIUs.

Conclusão Educação pré-natal e pós-parto mostraram um aumento significativo na escolha de métodos contraceptivos reversíveis de longa duração entre mães adolescentes. Grupos educativos realizados durante o pré-natal e além do período gestacional são ferramentas para promoção da saúde e são de fácil aplicação mundial, com baixa dependência de financiamento.

\section{Introduction}

The United Nations Sustained Development Goals aims to promote good health and well-being, quality education, gender equality, and to reduce inequalities-among other actions -to ensure prosperity for all. ${ }^{1}$ Adolescent pregnancy has been associated with social, economic, and health problems and, therefore, has been considered a public health issue, which can influence the level of human development. ${ }^{2,3}$ The global adolescent birth rate is 43.9 births/1,000 women aged 1519 years. In Brazil, this rate is 60.8/1,000, while in developed countries the rate is $<25 / 1,000 .{ }^{4}$ In 2016 in Brazil, one in five babies was born from adolescent girls and, similarly to other Latin American countries, Brazil has the highest number of pregnancies in adolescent girls under 14 years old. ${ }^{5}$

Almost $80 \%$ of adolescent pregnancies are unplanned, and between 28 and $63 \%$ of adolescent mothers had a repeated pregnancy within 18 months. ${ }^{6,7}$ Among girls with repeat pregnancies, two-thirds reported that the pregnancy was unplanned.

Long-acting reversible contraceptive (LARC) methods are intrauterine contraceptives (IUCs) and subdermal implants. These are the contraceptives with the highest efficacy and, consequently, an excellent tool to avoid repeated unplanned pregnancies. $6,8,9$

As the LARCS appear to be the best choice to avoid unplanned pregnancy among adolescents, we have searched our previous data and data from other countries to evaluate the choice of LARCs by adolescents. A previous study conducted by our group among postpartum adolescents in the same setting showed that only $11 \%$ chose IUCs as a contraceptive method (we do not have implants to offer at no cost) and depotmedroxyprogesterone acetate (DPMA) injection was chosen by $71 \% .{ }^{10}$ Furthermore, a large US-based study with more than 21,000 adolescents showed that, at the postpartum period, $15 \%$ chose IUCs and $7 \%$ chose implants as a contraceptive method. ${ }^{9}$

With the aim to increase the use of LARC methods among adolescents that do not want to get pregnant, since 2014 we have been performing educational semistructured group interventions with counseling during the prenatal care of the adolescent and immediately before the postpartum consultation. During these interventions, we promote antenatal education with the intent to empower the adolescent girls involved to choose the best contraceptive method according to their needs. The objective of our study was to evaluate whether our semistructured group interventions with counseling and an educative purpose increased the use of LARC methods at the postpartum consultation in young mothers.

\section{Methods}

A retrospective observational study was performed at the Department of Obstetrics and Gynecology, School of Medical Sciences of the Universidade Estadual de Campinas (UNICAMP, in the Portuguese acronym), Campinas, state of São Paulo, Brazil. The Ethical Committee of the UNICAMP approved this 
research (CAAE: 11909413.6.0000.5404). All of the items of the Strengthening the Reporting of Observational Studies in Epidemiology were followed.

Pregnant adolescents $<19$ years old attended prenatal care through our specialized service in taking care of adolescent pregnant/mothers. Currently, before medical consultation for antenatal and/or postpartum care, all of the adolescents $<20$ years old are invited to participate in an open group discussion during one hour with a multidisciplinary team to learn about human rights and, among these rights, options for contraception. Contraceptive methods; efficacy; and demystifying fears, misconceptions and preconceptions about the methods are openly discussed in these groups. All of the adolescents are also educated about the use of condoms as double protection. The adolescents participated in the group discussion in every antenatal care consultation. All of the adolescents spoke Portuguese, so there were no languages barriers.

A multiprofessional team conducted these groups in routine assistance. All of the information was provided to reduce the vulnerability of the adolescent mothers after delivery. Social and gender vulnerability was indicated in the population who attended at our hospital, which treats an underprivileged portion of the society.

The proposal to conduct a group with antenatal educational was intended to empower girls about human rights, which include sexual and reproductive rights, contraception and health knowledge, as well as to provide guidance on newborn care, breastfeeding, and on the rights of postpartum women. These antenatal groups also aimed to encourage education and healthy nutrition and physical activity counseling and to provide information on gender issues and violence.

We obtained data from medical records of all of the adolescents who underwent postpartum consultation. All data were routinely transcribed into a specific form and inserted into an Excel (Microsoft Corporation, Redmond, WA, USA) spreadsheet. Contraception methods were evaluated at three moments:

1) "Desired method" - the contraceptive method that the adolescent informed as desired at the $1^{\text {st }}$ postpartum consultation.

2) " $1^{\text {st }}$ Prescribed method" - the $1^{\text {st }}$ contraceptive method prescribed by the doctor and agreed by the adolescent after analyses of the desired method and after exposing characteristics of all methods available.

3) "Final method" - the final contraceptive method chosen after subsequent postpartum consultations that evaluated the adaptation and desire to change the contraceptive method. In our service, adolescents are routinely followed-up until 1 year after delivery. At this period, the acceptability of the contraceptive method with the desire to maintain the method chosen is evaluated.

In our service, IUC (both copper and the 52mg levonorgestrel-releasing intrauterine system), DMPA, combined oral contraceptives (COCs), progestin-only pills, once-a-month injectable contraceptives, and condoms are available at no costs. Implants are not available.
Statistical analyses were performed using the SAS Statistical Analysis System for Windows, version 9.2 (SAS Institute Inc., Cary, NC, USA) and included the use of the Fisher exact test, of the Kruskal-Wallis test, and of the Bowker test for symmetry. The level of significance was established at $5 \%$. Furthermore, as the intervention was applied for all of the adolescents that were in antenatal care in our service, the control group had to be historical (2011-2013). Therefore, we compared our actual rates of use of IUCs and DMPA with previous results in the same setting prior to the semistructured group interventions. ${ }^{10}$

\section{Results}

From January $1^{\text {st }} 2015$ through July $31^{\text {st }} 2017$, a total of 129 adolescents were included in the research data. Sociodemographic and obstetrics characteristics are shown in - Table $\mathbf{1}$. The mean ( \pm standard deviation [SD]) age of the teens and of their partners was $16.1( \pm 1.6)$ and $22.1( \pm 5.7)$ years old, respectively. Half of them (51\%) had a stable partner; nevertheless, $71 \%$ of the girls $<15$ years old were single.

Table 1 Sociodemographic and gynecologic characteristics, mode of delivery, and habits of postpartum adolescents

\begin{tabular}{|c|c|c|}
\hline Characteristics & $n$ & $\%$ \\
\hline \multicolumn{3}{|l|}{ Age (years old) $(n=129)$} \\
\hline$\leq 14$ & 24 & 18.6 \\
\hline$\geq 15$ & 105 & 81.3 \\
\hline \multicolumn{3}{|l|}{ Menarche (age) $(n=109)$} \\
\hline$\leq 12$ & 78 & 60.5 \\
\hline$\geq 13$ & 31 & 24.5 \\
\hline \multicolumn{3}{|l|}{ First sexual intercourse (age) $(n=99)$} \\
\hline$\leq 12$ & 9 & 9.0 \\
\hline $13-14$ & 54 & 54.5 \\
\hline$\geq 15$ & 36 & 36.5 \\
\hline \multicolumn{3}{|l|}{ Parity $(n=129)$} \\
\hline 1 & 115 & 89.15 \\
\hline$\geq 2$ & 14 & 10.85 \\
\hline \multicolumn{3}{|l|}{ Marital Status $(n=127)$} \\
\hline Single & 61 & 47.2 \\
\hline Stable partner & 66 & 51.1 \\
\hline Previous Contraceptive Method - Yes & 81 & 62.7 \\
\hline Currently Studying - Yes $(n=129)$ & 52 & 40.3 \\
\hline \multicolumn{3}{|l|}{ Schooling $(n=97)$} \\
\hline$\leq$ Elementary School & 38 & 29.4 \\
\hline$\geq$ High School & 59 & 45.7 \\
\hline Smoking Status - Yes $(n=119)$ & 5 & 3.8 \\
\hline Alcohol Consumption - Yes $(n=119)$ & 1 & 0.8 \\
\hline \multicolumn{3}{|l|}{ Mode of Delivery $(n=129)$} \\
\hline Vaginal & 92 & 71.3 \\
\hline Cesarean & 37 & 28.6 \\
\hline
\end{tabular}


Table 2 Correlation between desired, $1^{\text {st }}$ prescribed, and final contraceptive method used in adolescents after childbirth

\begin{tabular}{|c|c|c|c|c|c|c|c|}
\hline \multicolumn{2}{|c|}{ Desired method } & \multicolumn{3}{|c|}{$1^{\text {st }}$ Prescribed method } & \multicolumn{3}{|c|}{ Final method } \\
\hline \multicolumn{2}{|l|}{$n(\%)$} & \multicolumn{3}{|l|}{$n(\%)^{*}$} & \multicolumn{3}{|l|}{$n(\%){ }^{* *}$} \\
\hline & & IUC & DPMA & Others & IUC & DPMA & Others \\
\hline IUC & $41(32 \%)$ & $31(33 \%)$ & $9(9.6 \%)$ & 0 & $28(38 \%)$ & $4(5.4 \%)$ & $1(0.7 \%)$ \\
\hline DPMA & $42(32.5 \%)$ & $4(4.3 \%)$ & 37 (39\%) & 0 & $7(9.5 \%)$ & $25(34 \%)$ & $3(2.3 \%)$ \\
\hline Others & 46 (35.6\%) & 0 & 7 (5.4\%) & $6(4.6 \%)$ & 7 (9.5\%) & $3(4 \%)$ & $3(2.3 \%)$ \\
\hline
\end{tabular}

Abbreviations: DMPA, depot-medroxyprogesterone acetate; IUC, intrauterine contraceptive.

Bowker's test for symmetry: ${ }^{*} 0.62 ;{ }^{* *}$ Kappa $=0.57$; Missing $=35$ (for prescribed) / 48 (for final method).

Table 3 Adolescent satisfaction with current contraceptive methods

\begin{tabular}{|l|l|l|l|}
\hline Satisfaction & IUC & DMPA & Others \\
\hline Good (67) & $34(77.3 \%)$ & $30(76.2 \%)$ & $3(37 \%)$ \\
\hline Regular (16) & $8(18.2 \%)$ & $6(15.4 \%)$ & $2(25 \%)$ \\
\hline Bad (7) & $2(4.5 \%)$ & $3(7.7 \%)$ & $2(25 \%)$ \\
\hline Total & $44(100 \%)$ & $39(100 \%)$ & $7(100 \%)$ \\
\hline $\begin{array}{l}\text { Fisher exact test: } \\
\begin{array}{l}p=0.161 \\
\text { Missing=39 }\end{array}\end{array}$ & & \\
\hline
\end{tabular}

Abbreviations: DMPA, depot-medroxyprogesterone acetate; IUC, intrauterine contraceptive.

More than half (60.4\%) of the teens presented menarche at $<12$ years old, and the mean age for the 1 st sexual intercourse was $14.1( \pm 1.4)$ years old. A total of $63 \%$ percent of all the adolescents had ever used contraception before pregnancy, and the most frequently used method was COCs (33\%) followed by condoms (21\%). The main reasons for abandoning contraception were a desire of pregnancy (23.4\%) and irregular use of COCs (22.2\%).

Most of the girls involved had vaginal delivery (71.3\%), and cesarean delivery was performed due to pelvic cephalic disproportion in 6 cases, to acute fetal distress in 5 cases, and to maternal disease in 6 cases.
The 1st postpartum consultation occurred at $47.7( \pm 17.1)$ days after the delivery, and $32 \%$ of all the adolescents had already reinitiated sexual activity without protection. At this time, the contraceptive methods most frequently chosen by the adolescents were IUCs in 48 cases (37.2\%) and DMPA in 44 cases $(34.1 \%)$ (-Table 2 ).

The comparison among desired, $1^{\text {st }}$ prescribed, and final contraceptive methods chosen is shown in - Table 2. Onethird of the adolescents wished to use IUCs, DPMA or others. The satisfaction with the contraceptive method in 6 months to 1 year is in - Table 3 .

In the bivariate analysis, there were no differences among the contraceptive method chosen and the age of the adolescent, the age of the partner, years of schooling, age at menarche, and age at the $1^{\text {st }}$ sexual intercourse (data not shown). However, when we compared the historical rates of contraceptive methods used in our service during two different periods before and after the antenatal educational and counseling groups - there was a threefold increase in the use of IUCs (-Fig. 1).

\section{Discussion}

Our data showed an increase in the choice/insertion of IUCs at the $1^{\text {st }}$ postpartum consultation among adolescents after the implementation of counseling and educative groups.

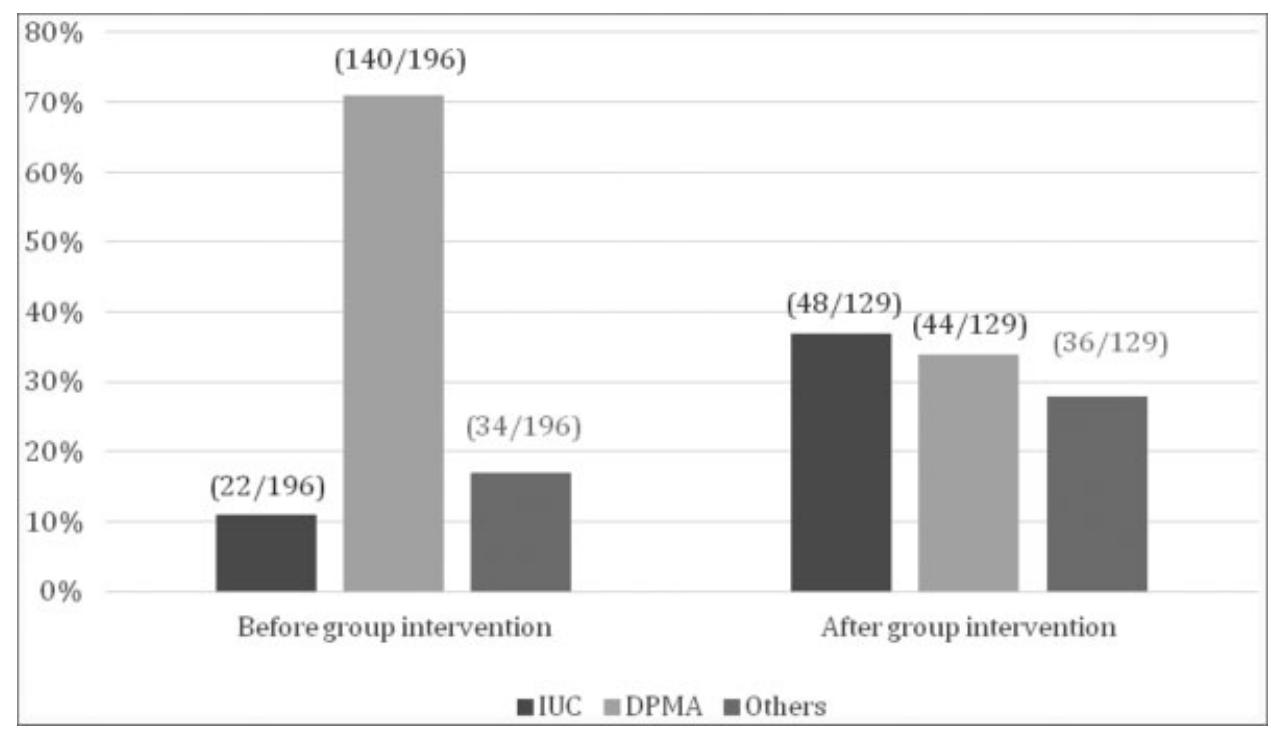

Fig. 1 Comparison among contraception choice before and after the education group. 
Previous data from our hospital showed an IUC rate use of only $11 \%{ }^{10}$; however, in the present study, IUCs were chosen by $37 \%$. These data supported our hypothesis that after information about contraceptive methods during group interventions, adolescents would choose more LARCs (represented in our service by IUCs).

The United Nations Sustained Development Goals include, among other topics, ensuring access to education, reducing inequality, promoting gender equity and empowering women and girls. ${ }^{1}$ For all these goals to be achieved, major transformations on a political level will need to be implemented, but daily actions can make a difference in starting these changes.

Only with effective educational intervention can adolescent girls choose the better contraceptive method according to their needs. In our sample, $77.5 \%$ of the girls chose to use a contraceptive method, and $37 \%$ of them chose IUCs. These findings are similar to one study that compared the rate of LARCs use by adolescent mothers before and after an intervention that included contraceptive counseling. ${ }^{11}$ The authors found that the LARCs rate used to be $40 \%$ among adolescents who were part of the intervention compared with $26 \%$ in the control group, representing a $13 \%$ increase in the use of LARCs in the intervention group. ${ }^{11}$

Contraceptive use among adolescents is still a complicated issue in many settings; ${ }^{12,13}$ nevertheless, it is well-established that LARC methods are the best contraceptive choice to avoid unplanned pregnancy. ${ }^{12-14}$ LARCs promote similar efficacy between typical and perfect use with only one intervention. $^{8,13,15}$

The postpartum period is an excellent opportunity to initiate contraception because, at this moment, women are motivated to avoid a new pregnancy. ${ }^{16}$ Nevertheless, many adolescents sometimes choose less-effective contraceptives or no contraceptive method at all at the postpartum period due to lack of adequate knowledge or access. ${ }^{17}$

Another thing that can make a difference is the time when contraceptive counseling is offered to adolescents during the postpartum period. A Thailand-based study compared the rate of choosing LARCs when contraceptive counseling was offered immediately after birth or within a conventional period (4-6 weeks after delivery). The authors found an odds ratio (OR) of 3.67 (rate of LARCs: $73.7 \%$ vs $42.6 \%$ ) among adolescents who received counseling immediately after birth. ${ }^{18}$

However, both in the immediate postpartum period and in the routine puerperal consultation, adolescent mothers should have a follow-up shortly after consultation because they present high discontinuation rates for the contraceptive methods. ${ }^{17}$ The use of LARCs could minimize this risk because it is a new opportunity that healthcare professionals have to reinforce contraceptive usage through counseling. After being clarified about the different contraceptive methods, about the characteristics of each of them and about the need to follow-up compose the reasons the adolescent mothers chose more LARCs in our study.

Although LARCs are apparently the best option for adolescents to avoid unintended pregnancy, the cost is the major reason to not use them. ${ }^{19}$ In our service, IUC (copper and hormonal) is the only LARC offered at no cost. The US
Contraceptive CHOICE Project offered any type of contraceptive methods at no cost and provided further information about contraceptive methods, including the high efficacy rates of LARCs. ${ }^{17}$ In that study, $72 \%$ of adolescents choose LARC methods. ${ }^{17}$ Among adolescents between 14 and17 years old, $63 \%$ chose LARC methods, whereas $29 \%$ of the women between 18 and 20 year old chose an implant. ${ }^{20}$ The researchers of the project also found that pregnancy, birth, and abortion were lower among adolescents participating in the study when compared with the general adolescent population of the St. Louis, MO, area. ${ }^{17}$

A recent large study in Latin America and the Caribbean shows that LARCs are seldom used. ${ }^{21}$ In Brazil, a big country with high rates of teenage pregnancy, LARCs were used in only $2 \%$ of all women. The study concluded that LARCs should be expanded and their use promoted, including among young and nulliparous women, and that family planning services, information and counseling should be provided. ${ }^{21}$

Our study presented some limitations. It was conducted in a single center and without the possibility to offer subdermal implants, which obviously affected the ability of the adolescents to choose LARCs. Nevertheless, the strength of the study was that with committed staff and without extra costs, we were able to implement contraception education through antenatal and postpartum consultations. This action promoted knowledge and broke barriers about IUCs in adolescent mothers.

The educational groups performed during antenatal care and extrapolating to educational groups for health promotion besides the gestational period is easy to be applied worldwide with low dependence on funding. Not only LARCs should be offered with no costs, but also education and specialty sexual education should be widespread. It is a start to promote health, gender equality, and empower women as the 2030 United Nations Sustained Development Goals Agenda aims to do.

In conclusion, contraception use to avoid a second pregnancy among young mothers involves political, social, economic, medical, and cultural issues, but can be achieved with low costs using a committed team. We need full-scale educational interventions for all adolescents - girls and boys - to explain the importance of using an effective contraceptive method to avoid unplanned pregnancies, and LARCs are a great alternative to reach this goal.

\section{Contributions}

Borovac-Pinheiro A. and Surita F. G. conceived and designed the study. Borovac-Pinheiro A. and Jesus E. A. $R$. collected the data. All of the authors were involved in the data analysis and interpretation. Borovac-Pinheiro A. and Surita F. G. were involved in writing. All of the authors approved the final version of the manuscript.

Conflicts of Interests

The authors have no conflict of interests to declare.

Acknowledgments

We thank Helymar Machado for the statistical analysis. 


\section{References}

1 United Nations Sustainable Development Summit 2015. https://sustainabledevelopment.un.org/post2015/summit. Accessed March 1, 2017.

2 United Nations Population Fund. Girlhood, not Motherhood: Preventing Adolescent Pregnancy. New York, NY: UNFPA; 2015https:// www.unfpa.org/sites/default/files/pub-pdf/Girlhood_not_motherhood_final_web.pdf. Accessed April 24, 2018.

3 Galvão RBF, Figueira CO, Borovac-Pinheiro A, Paulino DSM, FariaSchützer DB, Surita FG. Hazards of repeat pregnancy during adolescence: a case-control study. Rev Bras Ginecol Obstet 2018;40(08):437-443. Doi: 10.1055/s-0038-1666811

4 World Health Organization. World Health Statistics 2018: Monitoring Health for the SDGs, Sustained Development Goals. Geneva: WHO; 2018https://apps.who.int/iris/bitstream/handle/10665/272596/97 89241565585-eng.pdf?ua=1. Accessed April 29, 2018.

5 Chiarotti S. coord. Niñas Madres. Embarazo y Maternidad Infantil Forzada en América Latina y el Caribe. Buenos Aires: CLADEM; 2016http://clademargentina.com.ar/wp-content/uploads/2017/03/ Ni\%C3\%B1as-Madres-Balance-Regional.pdf. Accessed May 22, 2018.

6 Leftwich HK, Alves MVO. Adolescent Pregnancy. Pediatr Clin North Am 2017;64(02):381-388. Doi: 10.1016/j.pcl.2016.11.007

7 Meade CS, Ickovics JR. Systematic review of sexual risk among pregnant and mothering teens in the USA: pregnancy as an opportunity for integrated prevention of STD and repeat pregnancy. Soc Sci Med 2005;60(04):661-678. Doi: 10.1016/j. socscimed.2004.06.015

8 Ott MA, Sucato GS; Committee on Adolescence. Contraception for adolescents. Pediatrics 2014;134(04):e1257-e1281. Doi: 10.1542/ peds.2014-2300

9 Brunson MR, Klein DA, Olsen CH, Weir LF, Roberts TA. Postpartum contraception: initiation and effectiveness in a large universal healthcare system. Am J Obstet Gynecol 2017;217(01):55.e1-55. e9. Doi: 10.1016/j.ajog.2017.02.036

10 Borovac-Pinheiro A, Surita FG, D’Annibale A, Pacagnella RC, Pinto E Silva JL. Adolescent contraception before and after pregnancychoices and challenges for the future. Rev Bras Ginecol Obstet 2016;38(11):545-551. Doi: 10.1055/s-0036-1593971

11 Stevens J, Lutz R, Osuagwu N, Rotz D, Goesling B. A randomized trial of motivational interviewing and facilitated contraceptive access to prevent rapid repeat pregnancy among adolescent mothers. Am J Obstet Gynecol 2017;217(04):423.e1-423.e9. Doi: 10.1016/j.ajog.2017.06.010

12 Blumenthal PD, Voedisch A, Gemzell-Danielsson K. Strategies to prevent unintended pregnancy: increasing use of long-acting reversible contraception. Hum Reprod Update 2011;17(01): 121-137. Doi: 10.1093/humupd/dmq026

13 Trussell J, Wynn LL. Reducing unintended pregnancy in the United States. Contraception 2008;77(01):1-5. Doi: 10.1016/j. contraception.2007.09.001

14 Correia L, Martins I, Oliveira N, Antunes I, Palma F, Alves MJ. Contraceptive choices pre and post pregnancy in adolescence. J Pediatr Adolesc Gynecol 2015;28(01):24-28. Doi: 10.1016/j. jpag.2014.02.004

15 Faisal-Cury A, Tabb KM, Niciunovas G, Cunningham C, Menezes $\mathrm{PR}$, Huang $\mathrm{H}$. Lower education among low-income Brazilian adolescent females is associated with planned pregnancies. Int J Womens Health 2017;9:43-48. Doi: 10.2147/IJWH.S118911

16 Wilkie GL, Leung K, Kumaraswami T, Barlow E, Moore Simas TA. Effects of obstetric complications on adolescent postpartum contraception and rapid repeat pregnancy. JPediatr Adolesc Gynecol 2016;29(06):612-616. Doi: 10.1016/j.jpag.2016.05.002

17 Secura GM, Madden T, McNicholas C, et al. Provision of no-cost long-acting contraception and teenage pregnancy. N Engl J Med 2014;371(14):1316-1323. Doi: 10.1056/NEJMoa1400506

18 Kaewkiattikun K. Effects of immediate postpartum contraceptive counseling on long-acting reversible contraceptive use in adolescents. Adolesc Health Med Ther 2017;8:115-123. Doi: 10.2147/ AHMT.S148434

19 Fortier E, Foster AM. Exploring young mothers' experiences with postpartum contraception in Ottawa: results from a multimethods qualitative study. Contraception 2018;97(05):434-438. Doi: 10.1016/j.contraception.2017.12.017

20 Mestad R, Secura G, Allsworth JE, Madden T, Zhao Q Peipert JF. Acceptance of long-acting reversible contraceptive methods by adolescent participants in the Contraceptive CHOICE Project. Contraception 2011;84(05):493-498. Doi: 10.1016/j.contraception.2011.03.001

21 Ponce de Leon RG, Ewerling F, Serruya SJ, et al. Contraceptive use in Latin America and the Caribbean with a focus on long-acting reversible contraceptives: prevalence and inequalities in 23 countries. Lancet Glob Health 2019;7(02):e227-e235. Doi: 10.1016/S2214-109X(18)30481-9 